\title{
Origen, despliegue y exceso de la razón
}

Por Ricardo López Pérez

\section{Presentación}

Pensar con lógica es el sello del comportamiento intelectual en la cultura occidental. Racionalidad es la palabra que designa una modalidad del pensar que obtiene su legitimidad de principios universalmente aceptados. La cultura griega descubrió la razón que permite el intercambio entre los hombres, convirtiendo a la argumentación, la discusión y el diálogo en las condiciones necesarias para el despliegue intelectual, la búsqueda del conocimiento, y el establecimiento de las relaciones políticas. Con la aparición de la polis toma forma un sistema que hace posible la superioridad de la palabra por sobre las restantes formas del poder interpersonal, al punto que ésta llega a ser la mejor herramienta de influencia. Andando el tiempo la razón cometerá el exceso de representarse a sí misma como la expresión privilegiada de las capacidades humanas, descalificando otras propiedades del espíritu, e impidiendo el desarrollo de un pensamiento integrado y una conceptualización de la creatividad y las habilidades de orden superior. El sesgo de la razón, sin embargo, no puede ser planteado y superado saliéndose de la razón.

La razón es un descubrimiento de los griegos. Las leyes del pensamiento fueron observadas tempranamente en la antigua Grecia, y posteriormente expresadas y codificadas por diversos filósofos entre los que ciertamente debemos mencionar a Sócrates, Platón y Aristóteles. Grecia es para el filósofo Jorge Millas esencialmente la iniciadora de la idea y de la experiencia de una cultura racional. Una cultura creada libremente por hombres situados con una mirada consciente y crítica hacia las tradiciones, pero sin desprenderse necesariamente de ellas.

La historia de la filosofía asigna principalmente a Tales el mérito de introducir en la mente griega la vocación por la razón, que será responsable de crear una fuerte desconfianza en las narraciones del mito e iniciar nuevas formas de pensar y explicar. No siempre es fácil establecer la partida de nacimiento de un fenómeno tan complejo, pero este caso es distinto. Estamos en condiciones de fijar el lugar, el período y los padres de la razón griega. A principios del siglo $\mathrm{VI}$, en la ciudad de Mileto, en Jonia, primero Tales y luego Anaximandro y Anaxímenes, inauguran un modo de reflexión desembarazada de cualquier alusión a fuerzas sobrenaturales, provocada por el asombro y a partir de preguntas.

Estos son los pensadores con los que por primera vez el mundo que nos rodea, su origen y su orden, es representado explícitamente como un problema al que hay que buscar una respuesta acudiendo sólo a los recursos de la experiencia y del pensamiento. Una respuesta sin misterio, expuesta para ser comprendida por otros y debatida como cualquier evento de la vida cotidiana. Una forma del pensamiento en la cual las antiguas divinidades primordiales son reemplazadas por elementos de la naturaleza dotados de gran poder, y caracterizados como fuerzas imperecederas que a semejanza de los dioses poseen un extenso margen de acción. A diferencia de ellos, sin embargo, estas fuerzas concebidas en términos abstractos se limitan a producir efectos determinados y carecen de otra voluntad. Entra en escena un tipo de conocimiento libre, imperfecto, que requiere ser defendido, incluso justificado, no ya un regalo de origen superior sino el producto del esfuerzo humano, quedando instaladas de este modo las bases de la ciencia.

Por esa fecha contribuyen también a la declinación del mito los siete sabios, entre los cuales se cuenta al mismo Tales y personajes como Solón, que encarnan un tipo de inteligencia práctica al servicio de la comunidad. Representan una sabiduría vital que se ubica al margen de las teogonías, y es anterior a la fijación del saber a través de la escritura. Desde el siglo VI ponen en discusión el orden humano, tratan de definirlo y de traducirlo a fórmulas accesibles 
al pensamiento. Son hombres útiles que aportan su conocimiento y su consejo oportuno. Su sabiduría está plasmada en sentencias breves o máximas, verdaderos concentrados de sabiduría, referidas a la vida personal y a la actividad política. No tienen como objetivo el universo de la materia, sino el mundo de los hombres. Es cierto que el listado de nombres es variable, y persisten muchas dificultades para fijar históricamente su contribución, pero eso no corrige el hecho de que representan un intento por definir las bases de un nuevo orden que sustituye el poder divino, y aproximar a los hombres a su propia determinación.

Los griegos no carecen de explicaciones antes de Tales. Bajo la forma del mito se dispone de un poderoso recurso para desentrañar el origen de los fenómenos. El mito es a la vez una estructura de pensamiento y un sistema simbólico. Como tal describe, explica y ofrece soluciones, articula y organiza la experiencia. Se trata de un relato, de modo que si efectivamente resuelve problemas éstos no han sido planteados como tales. Apelando siempre a una autoridad, el mito consigue auto validarse, se asienta en una base sólida, indiscutida, en la tradición heredada, en los antiguos o en los dioses. No se divulga para ser debatido, y no necesita el sustento de una argumentación razonada. Ordena el mundo y está allí para ser aceptado.

Homero atribuye sus creaciones a alguna divinidad. En el comienzo de la llíada menciona a la diosa y en la Odisea a la musa, en cada caso como responsables de sus versos. El poeta Hesíodo, nacido en Boecia, hacia el siglo VII, dejó dos extensos poemas titulados Teogonía y Los Trabajos y los Días. Según su relato al pie del monte Helicón fueron las musas, compañeras de Apolo, hijas de Zeus y la Memoria, quienes le impusieron una misión fundamental revelándole una verdad que debía ser divulgada, lo que ha sido, lo que es y lo que será. En estos términos, fueron ellos por mucho tiempo los verdaderos maestros de la Hélade. Especialmente Homero, a quien Platón no pudo dejar de reconocer la condición de educador, del cual todos los hombres han aprendido desde el comienzo, llegó a ser el contenido obligado de todo afán pedagógico. Grandes creadores que sin embargo no se perciben como tales, sino como instrumentos de fuerzas superiores. Tanta mayor razón para aquilatar la envergadura del cambio que comenzaba a producirse.

Lo contrario ocurre cuando alguien apoyado en su propia razón aspira a ofrecer una explicación o proponer una interpretación. Una respuesta construida desde la propia actividad intelectual, por definición se obliga a proponer un discurso coherente sobre bases radicalmente distintas. La clave está en el fundamento, construido con unidad y de preferencia con tino. Cada propuesta ahora debe estar dispuesta a la crítica y al debate. Finalmente, sólo en el diálogo se puede establecer su legitimidad. Se consagra el valor de la pregunta, con su carga de provocación, y el derecho a la búsqueda personal. Tucídides, por ejemplo ya no habla de las musas, y al comienzo de su obra se nombra sin más como escritor.

En un sentido fundamental, surge la figura del filósofo como alguien que cultiva una actitud inquieta e interrogante frente al mundo, encarnando al mismo tiempo el poder de la especulación. Alguien que no repite simplemente lo que se dice, sino que pone su nombre cuando afirma o niega, asumiendo siempre la responsabilidad de defender lo dicho. El filósofo aspira a comprender el mundo y a comprenderse a sí mismo mediante el conocimiento, al que concibe como una obra individual, algo que se construye pacientemente. Anaxágoras hacia el siglo V propone una formula para resumir esta materia: Todas las cosas estaban juntas, después llegó la inteligencia y las ordenó. Cualquier diferencia entre un discurso y otro, entre distintas maneras de ordenar las cosas, expresa una contradicción que naturalmente provee la materia prima del diálogo, en el cual únicamente valen los argumentos y no la apelación a la autoridad. Werner Jaeger interpreta que la filosofía representa la suprema etapa de una nueva confianza en sí mismo por parte del hombre, bajo cuyos cimientos yace vencido un salvaje ejército de fuerzas tenebrosas.

Sin perjuicio de sus semejanzas, los filósofos tendrán distintos estilos y sus discursos se vestirán de variados ropajes. El formato más bien distante y sobrio, un ambicioso intento en prosa por encontrar la estructura de lo real desde la observación propuesto por Anaximandro, tendrá su contraste con el tono punzante y audaz de Jenófanes, a la vez rapsoda y filósofo, que expone en forma de sátira sus posiciones sobre los dioses y la verdad, o con el poema 
épico y didáctico de Parménides. A su vez, la libertad con que Jenófanes declama en cada lugar dispuesto a escuchar, rivaliza con el espíritu sectario de Pitágoras, quien opta por rodear de secreto sus hallazgos y comunicarlos sólo a un grupo selecto de iniciados. Heráclito, por su parte, un pensador solitario resuelto a desafiar los enigmas, que rehuye el contacto social y desprecia los cargos públicos, con un tono de profeta inaugura un estilo filosófico asentado en formulaciones lapidarias. Difiere de las formas que encarnan Anaxágoras, un modelo de intelectual puro muy cercano al gobierno de Pericles, el sofista Gorgias, principalmente un maestro de retórica, o Protágoras, fundador de una verdadera antropología racional, partidario de la democracia, maestro errante y asesor de gobierno. Por cierto, está también Sócrates que convierte el ágora en un aula, elevándose desde el monólogo hasta introducir el diálogo como la forma propia del intercambio filosófico, sin escribir jamás una línea, o bien su discípulo Platón, que en un sentido inverso encierra la filosofía en las paredes de la Academia, dando al diálogo una magnífica expresión literaria, distinto de Aristóteles y sus áridos tratados.

En todos ellos, puede decirse, la argumentación se convierte en una propiedad del lenguaje intelectual, dejando nula toda justificación para imponer o exigir sumisión. Cada cosa tiene valor mientras puede ser defendida, de modo que la energía de la duda está autorizada para actuar implacable con cualquier discurso que no pueda mostrar su fortaleza. La argumentación, la discusión y el diálogo comienzan a ser las condiciones que hacen posible el despliegue intelectual, y el avance en las materias del conocimiento. A continuación, serán también las condiciones para abordar los asuntos ciudadanos, para establecer y desarrollar las relaciones políticas.

En el comienzo no hay oposición, el mito es la palabra formulada y por tanto pertenece al ámbito del logos, esto es, al universo de lo que se dice. Cualquier parlamento equivale originalmente a un mito, el término no toma todavía el sentido de lo fabuloso o no verificable que tendrá gradualmente a partir de la nueva filosofía jonia. Logos primero es palabra y es discurso, pero terminará representando la razón. Progresivamente a medida que ya no designa sólo lo que se dice, sino más bien la palabra persuasiva cuando se dirige a una inteligencia racional, porque apela a lo verdadero, se establece una oposición entre ambas. Por una parte el logos como la palabra o el discurso racional, originando a su vez la palabra lógica, y el mito como algo ajeno a lo real y fuera de la racionalidad. Mito y logos tendrán por mucho tiempo, desde Tales y por lo menos durante el período clásico, una relación incierta y ambigua, de cercanía y distancia.

Es curioso advertir que la escritura no sobrevive al período micénico, y que los griegos necesitan redescubrirla hacia el siglo VIII tomándola de los fenicios. Es ahora una escritura fonética y definitivamente tiene otro carácter. Deja de ser la secreta especialidad de una clase de escribas al alero del poder, destinada a producir los archivos del rey, para convertirse en el instrumento que permite extender el conocimiento, y poner al alcance de todos las reflexiones sobre los distintos aspectos de la vida social y política.

El surgimiento y rápida extensión de la escritura favorecen la oposición entre mito y logos. La palabra escrita trae un nuevo pensamiento, que desplaza gradualmente todo el ambiente creado en torno a la oralidad. En el período clásico distintas manifestaciones literarias, que van desde discursos de oradores, tratados de medicina y gastronomía, hasta obras de historia, poesía trágica y ciertamente de filosofía, dan forma y ahondan estas diferencias. Teniendo como sede principal la ciudad de Atenas, en todos estos discursos escritos el logos se convierte en sinónimo de una argumentación racional, y en tensión permanente con el mito.

Estos procesos jamás carecen de matices, y suelen tener un desarrollo problemático. A título de ejemplo, Hipócrates no está dispuesto a justificar la ignorancia y argumenta: Porque si llamamos divinas a todas las cosas que no comprendemos, no existiría límite para las cosas divinas. Hecateo de Mileto desafía al mito en Las Genealogías cuando afirma: Lo que escribo es el relato de lo que me parece verdadero, pues los griegos cuentan demasiadas cosas, en mi opinión, ridículas. Heródoto de Halicarnaso, padre de la historia, en su texto titulado con posterioridad Los Nueve Libros de la Historia, defiende la noción de investigación con el propósito de desmarcarse del mito. La elección de la palabra historia no es casual, ya la 
había usado Tales, y equivale a búsqueda de información. Para Tucídides, de acuerdo a su Historia de la Guerra del Peloponeso, el historiador debe rechazar el mito, ligado a lo maravilloso, a fin de acercarse a lo verdadero. Jenófanes, nacido alrededor del 570 , se mostró escéptico respecto al conocimiento de la verdad. En su opinión todo no es sino un entramado de conjeturas. En La República de Platón se desacredita a los poetas y se establece la distancia entre la poesía, el mito, y el discurso verdadero, el logos, y finalmente la supremacía de este último.

Un aspecto decisivo de este proceso se despliega precisamente con la aparición de la polis. El surgimiento de la polis griega, reconocible con certeza a partir del siglo VII, es un acontecimiento de hondo impacto. Comúnmente llamada ciudad-estado, representa en la Hélade un verdadero cosmos social, la suma de todas las cosas divinas y humanas, tal como lo expresa Werner Jaeger. La vida social adquiere dimensiones hasta ese momento desconocidas. La polis encarna un sistema que afirma y hace posible la superioridad de la palabra por sobre las restantes formas del poder interpersonal, al punto que ésta llega a ser la herramienta de influencia por excelencia, la mejor manifestación de la autoridad intelectual, y la clave para el ejercicio del poder político y los derechos ciudadanos. En este ambiente surgen los sofistas, en el siglo $\mathrm{V}$, maestros errantes que inauguran el hábito de exigir honorarios por sus lecciones, llevando la enseñanza de la retórica, el arte de persuadir por medio de la palabra, hasta la cumbre de sus posibilidades.

La palabra cobra cada vez más fuerza, todavía más allá de los problemas del conocimiento y la política. Su poder se extiende hacia otros ámbitos. Desde antiguo la palabra curativa, orientada a enfrentar el penoso evento de la enfermedad, recurrió a formulas verbales de carácter mágico, principalmente ensalmos y conjuros. En los primeros domina la intención imperativa o coactiva ante una realidad que se quiere alejar, y en los segundos prevalece la súplica, de modo que su eficacia depende de una fórmula de encantamiento y de quien la emplea. Pero hacia el siglo $V$ se constituye una práctica terapéutica de la palabra, emerge un decir placentero o sugestivo, la palabra persuasiva se aplica a sanar, adopta una intención psicológica y se dirige directamente a producir un efecto en quien la escucha.

El sofista Antifón instala en Corinto el equivalente de una consulta psicológica, en la cual ofrece aliviar el pesar y la aflicción mediante la palabra. No es una osadía, sostiene Pedro Laín Entralgo, afirmar que el punto de partida de su doctrina es la oposición entre nomos, la convención, y physis, la naturaleza, que experimentan algunas personas. El hombre tiene el interés de observar la ley, pero en la soledad y sin testigos presta oídos al llamado de su naturaleza, afirma Antifón, porque la ley es accidental y la naturaleza es necesidad. Actuando persuasivamente, el sofista procura deshacer el nudo que provoca la tensión, llevando a la persona a un nuevo nomos más favorable, acorde con su physis.

En la polis la palabra no es una formula cerrada, misteriosa, que reclama obediencia, sino la materia prima del debate, del intercambio ciudadano. La polis hace posible la máxima extensión de todos los aspectos de la vida espiritual y social. La cultura griega, en particular en Atenas, se desarrolla generando un círculo cada vez más amplio en el que muchos más quedan integrados. Sin duda una transformación profunda: el conocimiento y las formas del pensar son llevados a la plaza pública. Es Sócrates, en estas condiciones, quien introduce el diálogo, incorporando la presencia activa del oyente. Al decir de Gastón Gómez Lasa, es el logos que echa a andar un nuevo logos, no forzosamente la repetición mecánica del logos escuchado.

El diálogo es un intercambio entre hombres libres a partir de preguntas y respuestas. Para Sócrates es el método que permite desarrollar el pensamiento y establecer el valor de la razón. A partir del diálogo se despliega la reflexión filosófica desde una pregunta inicial avanzando cada vez hacia nuevos niveles de complejidad y precisión. De acuerdo con Aristóteles, debemos a Sócrates el pensamiento inductivo y la definición universal. Tal confianza tiene el maestro en los alcances de la razón, que llega a asimilar el bien con el conocimiento y el mal con la ignorancia. En su mejor sentido, por tanto, conocer el bien es de inmediato ponerlo en práctica. Inversamente, hacer el mal sólo se explica y justifica por la 
ignorancia. Es en el pensamiento socrático en donde más claramente se observa la filosofía como una forma de vida guiada por la reflexión racional.

Del palacio micénico, cercado a las miradas, del núcleo aristocrático, donde sólo acceden los privilegiados, se pasa al ágora, el espacio público por definición. La polis pone a la mano el pensamiento y el conocimiento, y hace posible la democracia. Esta no es una relación casual, hay una conexión entre ambos procesos. Anaximandro ya había interpretado el mundo como la concurrencia de múltiples cualidades opuestas, en constante pugna, pero en donde finalmente prevalece el equilibrio. Afirmó que ningún elemento singular puede dominar a los demás por todo el tiempo. Es la igualdad y la simetría de los distintos elementos que constituyen la totalidad de lo existente, lo que caracteriza el orden de la naturaleza. La ampliación de esta idea lleva al concepto de un cosmos social regulado por la isonomía, cuyo ideal es el funcionamiento social bajo el imperio de instituciones regidas por normas, aplicadas por igual a cada miembro.

A esta interpretación se suma la concepción antilógica de Protágoras, que funda una incipiente teoría de la persuasión comenzando por reconocer que en todas las cosas hay dos razones contrarias entre sí. Sobre cada tema pueden hacerse varias proposiciones, aún contrapuestas, lo que en principio debilita cualquier criterio de objetividad destinado a obligar. A partir de este momento el sofista renuncia a la exclusividad en el plano de las ideas, y abre un espacio ilimitado a la comunicación y a la libertad de pensamiento y de acción. Con ello rompe la textura uniforme de la mirada privilegiada y da carta de ciudadanía a la diversidad. En conflicto con Sócrates, más interesado en la esencia de las cosas, la sentencia del hombre medida ahonda esta posición al sostener con énfasis que el hombre es la medida de todas las cosas, de las que existen como existentes, de las que no existen como no existentes. El hombre del que se habla tiene un sentido genérico, por ello es un error ver aquí únicamente una defensa de la individualidad. La polis está contenida en la sentencia, dado que también ella tiene el poder para establecer lo que es justo y bello, cuando así lo considere, y durante todo el tiempo que dure ese parecer.

El hombre puede construir su mundo sobre la base de sus propias posibilidades. No son los dioses, ni alguna autoridad externa superior, las fuerzas responsables de su destino. Las bases de la democracia están instaladas, y es en la Atenas clásica en donde esta forma de gobierno vivirá sus mayores contrastes, desde el intercambio simétrico entre ricos y pobres, la expresión libre de las opiniones, la participación activa en los asuntos públicos, como cuestiones religiosas, de seguridad pública o suministro de alimentos, hasta la aparición de la corrupción, la simulación y la intriga. La democracia, tal como la encontramos especialmente en tiempos de Pericles, es sin duda la expresión imperfecta de un intento de acuerdo para llevar los asuntos de la comunidad. Lo que se manifiesta es una obra humana, que se comprende mejor desde la razón y no desde la inspiración divina o una concepción estática de la verdad heredada. En adelante el orden social y la acción política aparecen como soluciones humanas y por tanto constantemente expuestas a nuevas transformaciones. Es en Atenas, en estas condiciones, en donde Peithó, la persuasión, elevada a la categoría de divinidad, tendrá su despliegue más llamativo, en contraste con Esparta, en donde el poder de Phobos, el temor, será el eje de la estabilidad social.

Es Atenas en donde las representaciones de las obras trágicas propondrán las preguntas más molestas para el sentido común, sometiendo a examen distintos aspectos de la vida pública, y examinando las profundidades del alma humana. Los orígenes de la tragedia están ligados a los festivales en homenaje a Dionisos, pero en su expresión madura ya no guarda semejanza con ningún culto. Atenas organizaba periódicamente concursos de tragedias que duraban tres días completos, cada uno asignado a un autor que presentaba tres tragedias encadenadas bajo la forma de una trilogía. Esquilo, Sófocles y Eurípides dominaron todo el siglo $\mathrm{V}$, escribiendo en total unas trescientas obras de las cuales conocemos treinta y dos. La tragedia toma sus contenidos del mito, pero no para repetirlos sino para recrearlos y someterlos a examen. Tal vez como pretexto para debatir los temas que inquietan a la polis, como la justicia, el poder, la guerra, el crimen, la culpa o el castigo. 
Los espectadores de la tragedia, hombres y mujeres, incluso jóvenes, están frente a la acción, pero fuera de ella. Si bien las emociones están presentes con gran fuerza, esta separación abre otras perspectivas a la mirada y al pensamiento, creando nuevas formas de conciencia y autoconciencia. Lo que hasta ese momento había sido privilegio de los dioses, ahora entra también a la condición humana: ser lejano espectador de los sufrimientos y conflictos de la vida humana, en la expresión de Charles Segal. La tragedia da una forma concreta a la experiencia intelectual que origina la razón, cuando los primeros filósofos jonios, llevados por el asombro que les provoca el espectáculo de la naturaleza, se separan de su objeto para comprenderlo mejor. Ver desde la distancia abre una nueva relación con las cosas, el ojo toma el control y posibilita una nueva experiencia mediada por el conocimiento. Conocer es una forma de ver. Ver y saber tienen para los griegos la misma raíz, como la tienen espectáculo y especulación, o contemplación y teoría. Del mismo modo, la palabra crítica deriva de krites, que significa juez, esto es, una persona que juzga desde fuera conforme a un criterio. A su vez criterio deriva de krinein, que tiene el sentido de separar. El sujeto que conoce es en fin alguien que observa lo que antes era desconocido.

Tras este largo y sinuoso proceso, pensar con lógica se convierte en el sello del comportamiento intelectual en la cultura occidental. En un sentido amplio, racionalidad es la palabra con la que designamos una modalidad del pensar que obtiene su legitimidad de leyes o principios universalmente aceptados. Desde este momento, el pensamiento se despliega conforme a principios lógicos que le otorgan carta de validez frente a cualquier interlocutor. Se trata de un pensamiento determinado por exigencias absolutas, pero siempre legítimo aunque pueda ser discutido.

La cultura griega inventó la razón que permite el intercambio entre los hombres. Esto es, aquella razón que con el lenguaje puede actuar sobre los hombres, definir las relaciones, construir un sentido de carácter interpersonal. Jorge Millas recurre a dos nociones para resumir la contribución de la cultura griega. La primera es la noción de cosmos, que expresa la idea de que la variedad de los fenómenos naturales constituye un todo ordenado, sometido a una regularidad, en donde cada cosa tiene un lugar. La noción de justicia, en segundo lugar, que fundamentalmente se refiere a la idea de orden aplicada al universo social, y según la cual también hay una racionalidad en el mundo de los valores aplicados a las relaciones entre los hombres. Desde luego, en el mundo de los hombres la polis es la depositaria privilegiada de estas dos concepciones.

Pero este tránsito de lo mítico a lo lógico, de un modo de vivir en el cual domina la implicación y la palabra remite a imágenes, a otro en que la palabra establece la distancia y nombra conceptos, supone un paso complejo que conlleva algunos potenciales sesgos y excesos. Con todo, es bueno tener en cuenta que la cultura griega no llegó nunca a ser enteramente racional. Paradojalmente, sus prácticas cotidianas se mantuvieron siempre traspasadas de religiosidad, y el mito no dejó de ser narrado tanto con fines educativos como rituales en todos los ámbitos de la polis. Los poemas de Homero, que tuvieron una versión escrita desde el siglo VIII, fueron utilizados ininterrumpidamente para mostrar los límites y grandezas del mundo humano y divino. El sofista Protágoras, en el diálogo platónico del mismo nombre, arranca de un mito sobre el origen del hombre para desarrollar sus argumentos sobre la enseñanza de la virtud. Los griegos no llegaron a confrontar de un modo radical el mundo divino con el humano. No se presenta como un dilema definir si la acción del hombre es el resultado de la voluntad o de una intervención divina. La interpretación más común, que presenta a la cultura griega completamente dominada por la racionalidad y la lógica, surge de considerar de preferencia ciertas fuentes filosóficas y desconocer el valor de otro tipo de fuentes, especialmente históricas.

La religiosidad griega fue muy profunda y arraigada en el quehacer cotidiano. La tentación de suponer que todos estos procesos de construcción de la racionalidad, se explican debido a la debilidad o insuficiente grado de desarrollo de la religión, es infundada. Una de las características de la polis es que no conoce la distinción entre lo sagrado y lo profano. La religiosidad, de hecho, impregna cada uno de sus gestos y movimientos, ya sea el inicio de una guerra, la fundación de una colonia, una asamblea, un simposio, un matrimonio o un contrato, todo se hará bajo la protección de una divinidad. Ningún ciudadano o habitante de 
la polis, poblada de templos e iconos, está al margen de las numerosas actividades de culto: procesiones, cánticos, danzas, coros, juegos y certámenes.

Se trata, sin embargo, de una religiosidad singular. Los principales ritos sagrados no requieren en modo alguno de intermediarios. No existe un texto único, ni un grupo privilegiado de interpretes o unos guardianes de la fe. No hay en la Hélade escritura sagrada, ni revelación, ni dogma, ni iglesia, ni sacerdotes, ni milagros. Creer en los dioses, participar en las grandes fiestas en su homenaje, peregrinar hacia los templos, respetar los oráculos, decir las plegarias y hacer las libaciones correspondientes, no son actividades reñidas con la posibilidad de pensar con un sentido propio y opinar desde sí mismo. Los habitantes de la polis miran de frente a sus dioses, en la oración están de pie, no arrodillados, con los brazos elevados y las palmas hacia arriba. Jean-Pierre Vernant dice que los hombres dependen de la divinidad y están a su servicio, porque sin su consentimiento nada puede realizarse en el mundo terreno, pero servicio no significa servidumbre.

Los dioses pertenecen al mundo cotidiano, pero no se ha creado un conocimiento de lo divino, la creencia no se instala en una estructura doctrinal. En este sentido, el terreno está despejado para nuevas búsquedas, aún al margen del culto, sin provocar necesariamente conflictos de poder o competencia.

Contemporáneamente, Gisela Labouvie-Vief ubica el mito en un renovado estatus cuando sostiene que las teorías del pensamiento deben asumir la existencia de dos modos de conocer, el mito y el logos, que siendo competitivos pueden funcionan perfectamente en una relación de colaboración. En el modo mito el pensamiento y el pensador, lo conocido y el conocedor, son una unidad indivisible, y a partir de este lazo se deriva el significado de la experiencia. El pensamiento y sus objetos no son extraños a la motivación y al estado interno de las personas. En el modo logos el significado se fragmenta de la experiencia y toma su sentido de sistemas de categorización estables e independientes. El conocimiento en esta modalidad se vuelve mecánico, simplemente derivado e inmanente.

La consecuencia más poderosa y desmedida, como consecuencia de reducir el mito a logos, fue la convicción racionalista que hizo de la mente algo que se puede describir sin referencia a una realidad intersubjetiva. Consumada esta reducción el pensamiento adopta su mejor expresión a través de fórmulas proposicionales, ideas universales y principios estables que no siempre guardan relación con la experiencia social. Con seguridad como expresión de ese ideal de hombre teórico del que habla Nietzsche en El Nacimiento de la Tragedia, trabajando únicamente al servicio de la ciencia y equipado con las más altas fuerzas cognitivas.

A su manera, Jerome Bruner también trae de vuelta al mito, cuando introduce una distinción entre dos modalidades del pensamiento, por una parte una modalidad paradigmática, y por otra una modalidad narrativa. Formas distintas y complementarias del funcionamiento cognitivo, y por tanto modos característicos de ordenar el mundo y construir la realidad. La distinción se apoya en la diferencia demostrable que existe entre argumento y relato. Ambos pueden usarse para demostrar y persuadir, pero no lo hacen de la misma manera, los argumentos convencen de su verdad, los relatos de su semejanza con la vida. En uno la verificación se hace acudiendo a procedimientos que aportan pruebas formales o empíricas, en el otro no se apela a la verdad sino a la verosimilitud, a lo que se acepta como posible. En la modalidad paradigmática o lógico matemática, se trata de establecer un sistema formal de descripción y explicación, sujeto a principios de validez absoluta, y con un lenguaje regulado por requisitos de coherencia y no-contradicción. En la modalidad narrativa, más cercana al mito, se producen buenos relatos obras dramáticas, crónicas creíbles, en las cuales la centralidad la tienen las vicisitudes de la acción y la intención humanas.

Pero si ha sido necesario decir estas cosas, es porque en algún punto se rompió el equilibrio. Efectivamente, andando el tiempo desde la experiencia griega esto es lo que ocurre de manera clara. La modernidad asume tal confianza en la razón que se sentirá autorizada para despreciar otras propiedades del espíritu. En sus célebres Meditaciones Metafísicas, Descartes termina descalificando a la imaginación. Luego de establecer sobre bases estrictamente racionales el fundamento de todo conocimiento verdadero y la existencia de dios, 
profundamente interesado en la unificación de las ciencias, afirma que ya no necesita la imaginación. Reconoce la fuerza de imaginar como algo que efectivamente existe en él, pero la concibe como algo muy distinto de la intelección o la concepción pura.

El paso siguiente es el más temerario y el de mayores consecuencias. Descartes afirma: Ese poder de la imaginación que poseo no es en ningún caso necesario a mi esencia (...) porque aunque no lo poseyera, seguiría siendo el mismo que soy ahora.

Por la misma época, comienzos del XVII, al filósofo inglés Francis Bacon, supone que se puede alcanzar el poder para controlar la naturaleza, mediante el descubrimiento de las leyes fundamentales que la gobiernan. En el libro Novum Organum propone un nuevo método para alcanzar un conocimiento seguro, científico, verdadero, apoyado en la observación y la inducción. Se encuentra convencido que a partir de estas prácticas rigurosas se pueden superar los distintos obstáculos que hasta ese momento han frenado la búsqueda del conocimiento. Para expresar estos obstáculos, que son al mismo tiempo errores, elabora el concepto de ídolo. Están los ídolos de la tribu, relativos a la naturaleza humana, los ídolos de la caverna, que incluyen la confianza infundada en la información que aportan los sentidos, los ídolos del mercado, en donde se ubican los engaños que provienen del mal uso del lenguaje, y los ídolos del teatro, referidos a las fábulas legadas por los filósofos.

En su entusiasmo sin límites, Bacon llega a también a descalificar a la imaginación: La imaginación difícilmente produce ciencia (...) debe entenderse más bien como placer o juego de ingenio antes que como ciencia.

La razón es superior, la imaginación carece de méritos. Así queda establecido después de una larga tradición en que la racionalidad hace su despliegue hasta un punto en que ya no tiene contrapeso. Una profunda desconfianza en la imaginación aparece tempranamente con Platón, claramente visible en su proyecto de excluir de su república ideal al mito y a los poetas, que son sus representantes directos: Por estos motivos, hay que poner término a mitos semejantes, para no producir en nuestros jóvenes una gran facilidad para hacer el mal. El clímax de este proceso no tarda en llegar, se produce cuando se asimila ciencia y conocimiento. La ciencia aparece como el grado más alto de conocimiento posible, como el conocimiento por excelencia, y como una actividad que progresa por acumulación, convencida de que puede lograr la objetividad a partir de observaciones neutrales.

Nuestra cultura en muchas de sus manifestaciones está empapada de estas concepciones. De pronto ya no recordamos los nombres de los filósofos, ni de sus obras, ni los procesos que subyacen, pero ellos respiran detrás de nuestras formas de ser y de hacer. De nada vale negar su existencia cuando su influencia está inadvertidamente, de un modo subterráneo, en numerosas prácticas habituales ligadas a nuestra experiencia intelectual y social.

Una de las características decisivas de esta racionalidad es su tendencia a pensar apoyado en antítesis o dicotomías. Es decir, representar la experiencia o los fenómenos a partir de oposiciones irreconciliables, cuyos extremos se afirman a sí mismos y no requieren de su contrario. Sueño y vigilia, alma y cuerpo, análisis y síntesis, teoría y práctica, pecado y virtud, realismo y nominalismo, son sólo algunos ejemplos célebres de una lista interminable. Esta forma de pensar es la que Hegel nombra en su Ciencia de la Lógica con la expresión entendimiento reflexivo, en una clara manifestación de la reflexión y crítica que la filosofía hace sobre su propio pensar.

Para Hegel el entendimiento reflexivo se apoderó de la filosofía y le impuso sus determinaciones. Esto significa que se instaló el dominio de un tipo de pensamiento que abstrae y por tanto separa y que insiste en sus separaciones. Toda la reflexión filosófica se ha proyectado en los estrechos márgenes de distinciones rígidas, insalvables, que hacen impracticable el proyecto de un pensamiento integrado, capaz de reconocer la unidad y la articulación de las cosas. De este modo, la filosofía, a su juicio, llega a un callejón sin salida que sólo puede superarse mediante un movimiento de elevación a la razón, entendido como 
el punto en que puede observarse la identidad y la diferencia sin que ello resulte en una contradicción.

Podría pensarse que este recorrido cumplido en la cultura griega, desde el imperio de las fuerzas sobrenaturales hasta el pensamiento libre e independiente, contenía ya el germen del exceso, pero lo cierto es que durante el período clásico los signos de la desmedida aún no asignan todo el protagonismo a la razón. Los elementos irracionales jamás desaparecieron de la cultura griega, como lo ha destacado E. R. Dodds, quien sostiene que los filósofos creadores del primer racionalismo occidental fueron profunda e imaginativamente conscientes del poder, el misterio y el peligro de lo irracional. Del mismo modo, Wilhelm Nestle afirma que no encontramos ningún otro pueblo en donde se manifieste un mayor equilibrio de la fantasía y el entendimiento, de la capacidad de creación plástica con la capacidad de abstracción. Un sentido de la proporción, que de acuerdo a su análisis, los libró tanto de un intelectualismo seco y estéril cuanto de una degeneración de la fantasía en monstruosidad. La especulación filosófica griega aspiraba a apropiarse de la totalidad de la existencia, pero el pensamiento no está encerrado en sí mismo y no propicia todavía fracturas tajantes como las que se producirán después entre ciencia y religión, por ejemplo. Werner Jaeger sostiene que los griegos no conocieron en absoluto semejantes reinos autónomos del espíritu.

La cultura griega tampoco produjo al individuo en el sentido estricto del término. La famosa máxima, atribuida a los siete sabios, e inscrita en el Templo de Apolo en Delfos, conócete a ti mismo, no expresa una invitación a refugiarse en un mundo interior completamente ajeno a lo que lo rodea. Tampoco busca privilegiar un espacio de pensamiento interior auto suficiente, una subjetividad impenetrable para el resto, como en cierto modo aparecerá posteriormente con el cogito cartesiano. Lo que realmente distinguía al hombre griego era precisamente que vivía al interior de la polis, una forma de organización social completa y superior. Un animal político según la definición de Aristóteles. Pensarse a sí mismo, por tanto, implicaba sin duda pensar también en el mundo, dentro del mundo y con el mundo. El hombre pertenece al mundo, afirma Jean-Pierre Vernant, y por ello está inevitablemente emparentado con él, y si llega a conocerlo es por resonancia y connivencia. Solamente así llega a conocerse en su condición de mortal, orientado a un fin, pero sin posibilidad de igualarse a los dioses, limitado y efímero.

Fueron los siglos posteriores los que rompieron el necesario equilibrio, consagrando el sesgo de la razón. Más aún, en la actualidad no es infrecuente encontrar el hábito de abordar la crítica a los excesos de la razón acudiendo a otros excesos de signo contrario. Eso, sin embargo, es un círculo vicioso y no resuelve ningún problema. No hay modo de salirse de la razón, refugiarse en alguna forma de irracionalidad, y pretender ser escuchado y comprendido. No hay argumento posible, ni una narración, que puedan aspirar a una validez intersubjetiva fuera de una racionalidad compartida. La razón está obligada a pensarse a sí misma y al hacerlo no tiene más alternativa que partir de su propia historia.

Bibliografía:
Bacon, Francis. Ensayos. Aguilar. Madrid. 1961.

Bermejo Barrera, J. C. y otros. Los Orígenes de la Mitología Griega. Akal. Madrid. 1996.

Bruit, Louise y Schmitt, Pauline. La Religión Griega en la Polis de la Época Clásica. Akal. Madrid. 2002.

Bruner, Jerome. Realidad Mental y Mundos Posibles. Gedisa. Barcelona. 2001.

De Romilly, Jacqueline. Los Grandes Sofistas en la Atenas de Pericles. Seix Barral. Barcelona. 1997.

Descartes, René. Obras Escogidas. Sudamericana. Buenos Aires. 1967.

Dodds, E. F. Los Griegos y lo Irracional. Alianza. Madrid. 1993. 
García Gual, Carlos. Los Siete Sabios (y Tres Más). Alianza. Madrid. 1989.

Gómez Lasa, Gastón. El Expediente de Sócrates. Universitaria. Santiago. 1992.

Gómez Lasa, Gastón. La Institución del Diálogo Filosófico. Universidad Austral. Valdivia. 1980.

Hegel G. W. F. Ciencia de la Lógica. Solar/Hachette. Buenos Aires. 1968.

Hegel G. W. F. Lecciones Sobre la Historia de la Filosofía. FCE. México. 1985.

Hesíodo. Los Trabajos y los Días. Universitaria. Santiago. 1995.

Homero. Obras Completas. Montaner y Simón. Barcelona. 1955.

Jaeger, Werner. Paideia. Los Ideales de la Cultura Griega . FCE. México. 1967.

Jaeger, Werner. La Teología de los Primeros Filósofos Griegos. FCE. México. 2000.

Labouvie-Vief, Gisela. La Sabiduría Como Pensamiento Integrado. En Stenberg, Robert (Editor). 1994.

Lain Entralgo, Pedro. La Curación por la Palabra en la Antigüedad Clásica. Anthropos. Barcelona. 1987.

López, Ricardo. Maestros Innovadores. Universidad de Chile. Santiago. 1997.

Llanos, Alfredo. Los Presocráticos y sus Fragmentos. Juárez. Buenos Aires. 1968.

Millas, Jorge. Ensayos Sobre la Historia Espiritual de Occidente. Universitaria. Santiago. 1960.

Millas, Jorge. Idea de la Filosofía. Universitaria. Santiago. 1970.

Nestle, Wilhelm. Historia del Espíritu Griego. Ariel. Barcelona. 1987.

Nietzsche, Friedrich. El Nacimiento de la Tragedia. Alianza. Madrid. 1995.

Platón. La República. Universidad Austral. Valdivia. 1983.

Rodríguez Adrados, Francisco. La Democracia Ateniense. Alianza. 1993.

Segal, Charles. El Espectador y el Oyente. En Vernant Jean-Pierre (Editor). 1995.

Sternberg, Robert (Editor). La Sabiduría. Desclée de Brouwer. Bilbao. 1994.

Vernant, Jean-Pierre. Los Orígenes del Pensamiento Griego. Paidós. Barcelona. 1998.

Vernant, Jean-Pierre. Mito y Pensamiento en la Grecia Antigua. Ariel. Barcelona. 2001.

Vernant, Jean-Pierre (Editor). El Hombre Griego. Alianza. Madrid. 1995. 